\title{
Pengaruh Pengetahuan Dan Dukungan Keluarga Terhadap Pemanfaatan Posyandu Usia Lanjut Di Desa Sikoran Kecamatan Danau Paris Kabupaten Aceh Singkil
}

\author{
Yusraa $^{1}$ \\ ${ }^{1}$ Dosen STIKes Putra Abadi Langkat Stabat \\ Email: yusraa925@gmail.com
}

\section{ABSTRACT: EFFECT OF KNOWLEDGE AND USE OF FAMILY SUPPORT FURTHER POSYANDU AGE IN THE VILLAGE OF LAKE DISTRICT PARIS SIKORAN ACEH SINGKIL}

Background Background: At this time the population of the elderly is increasing, therefore the government has formulated various policies for elderly health services. The aging process should be accompanied by the ability and awareness of the elderly in playing a role to be actively involved in the utilization of posyandu. The low percentage of elderly visits in the work area of the Danau Paris Puskesmas, Danau Paris District, was due to the lack of knowledge of the elderly about the benefits of the posyandu, then a lack of support from the family or family attention to the elderly because they were busy with their respective activities.

Purpose. The purpose of this study was to determine the effect of knowledge, and family support for elderly Posyandu utilization in the village Sikoran Lake District of Aceh Singkil Paris.

Method Design of this study is a survey using explanatory research approach. The population of this research is all elderly people in the village Sikoran Lake District of Paris. A population of 57 people and sample using total sampling. Data were collected by using a questionnaire distributed to the elderly. The data analysis using logistic regression.

Results: Results of analysis of knowledge on the utilization of Posyandu elderly based on the knowledge obtained by logistic regression test ( $p=0.000$ $<0.05$ ), then there is a significant effect so $\mathrm{Ha}$ is received. Results of analysis of family support was obtained $(p=0.085>0.05)$, the Ha rejected.

Conclusion:The results of this study suggested to To the leaders in order to further improve the management of health centers, especially the supervision of health personnel and support of cadres Posyandu elderly in order to improve the health of the elderly.

Keywords: Awareness, Family Support, Utilization of Posyandu Elderly

\footnotetext{
Yusraa $^{1}$

${ }^{1}$ Dosen STIKes Putra Abadi Langkat Stabat

Email: yusraa925@gmail.com
} 
INTISARI: PENGARUH PENGETAHUAN DAN DUKUNGAN KELUARGA TERHADAP PEMANFAATAN POSYANDU USIA LANJUT DI DESA SIKORAN KECAMATAN DANAU PARIS KABUPATEN ACEH SINGKIL

Latar Belakang: Populasi Lanjut Usia (Lansia) pada masa ini semakin meningkat, oleh karena itu pemerintah telah merumuskan berbagai kebijakan pelayanan kesehatan usia lanjut. Proses penuaan hendaknya diiringi dengan kemampuan dan kesadaran lansia dalam menampilkan peranan untuk terlibat secara aktif dalam pemanfaatan posyandu. Rendahnya persentase kunjungan lansia di wilayah kerja Puskesmas Danau Paris Kecamatan Danau Paris dikarenakan kurangnya pengetahuan lansia tentang manfaat dari posyandu tersebut, kemudian kurangnya dukungan dari pihak keluarga atau perhatian keluarga kepada lansia karna sibuknya dengan aktifitas masing-masing.

Tujuan :Tujuan penelitian ini adalah untuk mengetahui pengaruh pengetahuan, dan dukungan keluarga terhadap pemanfaatan posyandu lanjut usia di Desa Sikoran Kecamatan Danau Paris Kabupaten Aceh Singkil.

Metode: Desain penelitian ini bersifat survei dengan menggunakan pendekatan explanatory research. Populasi penelitian ini adalah seluruh lansia yang ada di Desa Sikoran Kecamatan Danau Paris. Populasi berjumlah 57 orang dan sampel menggunakan total sampling. Metode pengumpulan data dengan menggunakan kuesioner yang dibagikan kepada lansia. Analisis data menggunakan regresi logistic.

Hasil : analisa pengetahuan terhadap pemanfaatan posyandu usia lanjut berdasarkan pengetahuan dengan uji regresi logistik diperoleh $(p=0,000<$ $0,05)$, maka ada pengaruh yang signifikan maka Ha diterima. Hasil analisa dukungan keluarga diperoleh $(p=0,085>0,05)$ maka Ha ditolak.

Kesimpulan: Hasil penelitian ini disarankan kepada Kepada pimpinan agar lebih meningkatkan manajemen Puskesmas khususnya pengawasan terhadap tenaga Kesehatan dan dukungan dari kader posyandu lanjut usia. agar dapat meningkatkan derajat kesehatan pada lanjut usia.

Kata Kunci : Pengetahuan, Dukungan Keluarga, Pemanfaatan Posyandu Usia Lanjut

\section{PENDAHULUAN}

Populasi Lanjut Usia (Lansia)

pada masa ini semakin meningkat, oleh karena itu pemerintah telah merumuskan berbagai kebijakan pelayanan kesehatan usia lanjut ditujukan untuk meningkatkan derajat kesehatan dan mutu kehidupan lansia untuk mencapai masa tua bahagia dan berdaya guna dalam kehidupan keluarga dan masyarakat sesuai dengan keberadaannya (Nasution, 2013). Sebagai wujud nyata pelayanan sosial dan kesehatan pada kelompok usia lanjut ini, pemerintah telah mencanangkan pelayanan pada lansia melalui beberapa jenjang, diantaranya pelayanan kesehatan di tingkat masyarakat yaitu Pos Pelayanan Terpadu (Posyandu) Lansia (Yuniati \& Dewi, 2014).

Menurut WHO di seluruh dunia penduduk Lansia usia 60 tahun ke atas bertumbuh dengan sangat cepat bahkan tercepat dibanding kelompok usia lainnya. Diperkirakan mulai tahun 2010 akan terjadi ledakan 
jumlah penduduk lanjut usia. Hasil prediksi menunjukkan bahwa persentase penduduk lanjut usia akan mencapai 9,77 persen dari total penduduk pada tahun 2010 dan menjadi 11,34 persen pada tahun 2020 (Kurniawati \& Hasanah, 2019). Meningkatnya angka harapan

hidup merupakan salah satu indikator keberhasilan pembangunan kesehatan di Indonesia. Dilihat dari sisi ini pembangunan kesehatan di Indonesia sudah cukup berhasil, karena angka harapan hidupnya meningkat secara bermakna yaitu 69,65\% di tahun 2011 menjadi 72 tahun di tahun 2012. Namun demikian angka harapan hidup yang meningkat ini justru membawa beban bagi masyarakat, karena populasi penduduk usia lanjut yang meningkat ini mengakibatkan kelompok resiko dalam masyarakat menjadi lebih tinggi (Latifah, Abi Muhlisin \& Ambarwati, 2013). Berdasarkan laporan Kementerian Kesehatan RI tahun 2012, jumlah penduduk lanjut usia di Indonesia pada tahun 1990 sebesar 11,3 juta jiwa $(6,4 \%)$ meningkat menjadi 15,3 juta $(7,4 \%)$ pada tahun 2000. Pada tahun 2010 diketahui bahwa jumlah lansia sama dengan jumlah anak balita yaitu sekitar 24 juta jiwa atau 9,77\% dari seluruh jumlah penduduk. Sementara pada tahun 2020 diperkirakan jumlah lansia akan meningkat menjadi 28,8 juta atau $11,34 \%$ dari total jumlah penduduk (Maryam, 2008).

Masalah utama bagi para lanjut usia adalah pemenuhan kebutuhan pelayanan kesehatan, oleh karena itu perlu dikembangkan pelayanan kese-hatan yang lebih mengutamakan upaya peningkatan, pencegahan, dan peme-liharaan kesehatan disamping upaya penyembuhan dan pemulihan. Langkah-langkah konkrit yang harus dilaksanakan secara berkesinambungan dalam rangka peningkatan derajat kesehatan lanjut usia untuk mencapai lanjut usia yang sehat, mandiri, aktif, produktif dan berdaya guna bagi keluarga dan masyarakat adalah de-ngan pemanfaatan Posyandu Lansia (Mengko, 2015).

Dukungan keluarga terhadap lansia dapat berupa dukungan informasi. Dukungan ini diberikan dengan cara memberi informasi, nasehat, dan petunjuk tentang cara penyelesaian masalah. Keluarga juga merupakan penyebar informasi yang dapat diwujudkan dengan pemberian dukungan semangat, serta pengawasan terhadap pola kegiatan sehari-hari (Zakir, 2017). Aspekaspek dalam dukungan ini adalah nasehat, usulan, saran, petunjuk dan pemberian informasi. Dukungan informasional adalah dukungan berupa pemberian informasi yang dibutuhkan oleh individu. Keluarga dapat menyediakan informasi yang dibutuh-kan lansia dengan menyarankan tentang dokter, terapi yang baik bagi dirinya, dan tindakan spesifik bagi individu untuk melawan stressor (Nasution, 2013).

Hasil survei awal menunjukkan bahwa dari 57 lansia hanya 22 lansia yang melakukan kunjungan ke Posyandu lansia Desa Sikoran Kecamatan Danau Paris Kabupaten Aceh Singkil. Hal ini sangat jauh dari target yang telah ditetapkan yaitu minimal $70 \%$ atau 40 lansia. Berdasarkan hal tersebut peneliti tertarik untuk melakukan penelitian mengenai Pengaruh Pengetahuan dan Dukungan Keluarga Terhadap Pemanfaatan Posyandu Lansia di Desa Sikoran Kecamatan Danau Paris Kabupaten Aceh Singkil. 


\section{METODE PENELITIAN}

Jenis penelitian ini merupakan penelitian survei dengan menggunakan pendekatan explanatory research atau penelitian penjelasan yang bertujuan untuk menjelaskan pengaruh pengetahuan dan dukungan keluarga terhadap pemanfaatan posyandu lanjut di desa sikoran Kecamatan Danau Paris Kabupaten Aceh Singkil.

Data dikumpulkan melalui pengumpulan data primer yaitu melalui kuesioner yang diberikan peneliti dan wawancara langsung di desa sikoran Kecamatan Danau Paris Kabupaten Aceh Singkil. ata sekunder adalah data yang diperoleh dari catatan dan laporan kader untuk mengetahui jumlah kelompok lanjut usia yang ada di desa sikoran
Kecamatan Danau Paris Kabupaten Aceh Singkil. Penelitian ini dilakukan di Desa Sikoran di wilayah kerja Puskesmas Danau Paris Kecamatan Danau Paris Kabupaten Aceh Singkil

Populasi penelitian ini adalah seluruh lansia di Desa Sikoran sebanyak 57 lansia. Sampel penelitian ini adalah seluruh lansia yang ada di desa Sikoran yaitu sebanyak 57 lansia.

Uji statistik yang digunakan adalah uji korelasi Pearson Product Moment pada tingkat kepercayaan 95\% dengan menggunakan program komputer (SPSS), dimana taraf signifikan sebesar 0,05 , sehingga bila ditemukan hasil analisis statistik $\mathrm{p}<0,05$ maka variabel dinyatakan berhubungan secara signifikan.
HASIL

Tabel 1.

Tabulasi Silang Pengetahuan Lansia Dengan Pemanfaatan Posyandu Lansia Di Desa Sikoran Kecamatan Danau Paris Kabupaten Aceh Singkil Tahun 2019. responden terdapat 33 responden $(57,9 \%)$ yang menyatakan pengetahuan kategori baik dengan Pemanfaatan kategori baik sebanyak $32(86,5 \%)$, dan dari 24 responden $(42,1 \%)$ yang menyatakan pengetahuan kurang dengan pemanfaatan baik sebanyak 5

\begin{tabular}{|c|c|c|c|c|c|c|c|}
\hline \multirow{3}{*}{$\begin{array}{l}\text { Peng } \\
\text { etah } \\
\text { uan }\end{array}$} & \multicolumn{4}{|c|}{ Pemanfaatan } & \multirow{2}{*}{\multicolumn{2}{|c|}{ Total }} & \multirow{2}{*}{$\begin{array}{l}\text { Sigresponden }(13,5 \%) \cdot(5) \\
(P) \quad \text { Setelah dilakukan uji statistik }\end{array}$} \\
\hline & \multicolumn{2}{|c|}{ Baik } & \multicolumn{2}{|c|}{ Kurang } & & & \\
\hline & $\mathbf{F}$ & $\%$ & $\mathrm{~F}$ & $\%$ & $\mathbf{F}$ & $\%$ & (uji Chi-Square), diperoleh nilai $P=$ \\
\hline Baik & $\begin{array}{l}3 \\
2\end{array}$ & 86.5 & 1 & 5.0 & 33 & 9 & $\begin{array}{l}0.000 \text { memperhatikan bahwa nilai } \\
0 . \text { osignifikan } P<a=0.05 \text {. maka dapat }\end{array}$ \\
\hline $\begin{array}{l}\text { Kura } \\
\text { ng }\end{array}$ & 5 & 13.5 & $\begin{array}{l}1 \\
9\end{array}$ & $\begin{array}{c}95 . \\
0\end{array}$ & 24 & 42.1 & $\begin{array}{l}\text { o0disimpulkan bahwa ada hubungan } \\
\text { antara pengetahuan dengan }\end{array}$ \\
\hline $\begin{array}{l}\text { Jum } \\
\text { lah }\end{array}$ & $\begin{array}{l}3 \\
7\end{array}$ & $\begin{array}{c}100 . \\
0\end{array}$ & $\begin{array}{l}2 \\
0\end{array}$ & $\begin{array}{c}10 \\
0\end{array}$ & $\begin{array}{l}5 \\
7\end{array}$ & $\begin{array}{l}100 \\
.0\end{array}$ & $\begin{array}{l}\text { pemanfaatan posyandu lansia Di } \\
\text { Desa Sikoran Kecamatan DAnau Paris }\end{array}$ \\
\hline
\end{tabular}

Berdasarkan tabel 1. di atas dapat diketahui bahwa dari 57

\footnotetext{
Yusraa $^{1}$

${ }^{1}$ Dosen STIKes Putra Abadi Langkat Stabat

Email: yusraa925@gmail.com
} 
Tabel 2.

Tabulasi Silang Dukungan Keluarga Terhadap Pemanfaatan Posyandu Lansia di Desa Sikoran Kecamatan Danau Paris Kabupaten Aceh Singkil

\begin{tabular}{|c|c|c|c|c|c|c|c|}
\hline \multirow{3}{*}{$\begin{array}{l}\text { Dukungan } \\
\text { Keluarga }\end{array}$} & \multicolumn{4}{|c|}{ Pemanfaatan } & \multirow{2}{*}{\multicolumn{2}{|c|}{ Total }} & \multirow{3}{*}{$\begin{array}{l}\text { Sig } \\
\text { (p) }\end{array}$} \\
\hline & \multicolumn{2}{|c|}{ Baik } & \multicolumn{2}{|c|}{ Kurang } & & & \\
\hline & $F$ & $\%$ & $\mathrm{~F}$ & $\%$ & $\mathbf{F}$ & $\%$ & \\
\hline Baik & 11 & 29.7 & 1 & 5.0 & 12 & 21.1 & 0.0 \\
\hline Kurang & 26 & 70.3 & 19 & 95.0 & 45 & 78.9 & 85 \\
\hline Jumlah & 37 & 100.0 & 20 & 100.0 & 57 & 100.0 & \\
\hline
\end{tabular}

Berdasarkan tabel 2. di atas dapat diketahui bahwa dari 57 responden terdapat 12 responden $(21,1 \%)$ yang menyatakan dukungan keluarga kategori tidak baik dengan pemanfaatan kategori tidak baik sebanyak $15,0 \%$ ), dan 45 responden $(78,9 \%)$ yang menyatakan dukungan keuarga tidak baik dengan pemanfaatan tidak baik sebanyak 19 responden $(95,0 \%)$

\section{PEMBAHASAN}

1. Pengetahuan Lansia Dengan Pemanfaatan Posyandu Lansia Di Desa Sikoran Kecamatan Danau Paris Kabupaten Aceh Singkil Tahun 2019.

Setelah dilakukan uji statistik (uji Chi-Square), diperoleh nilai $P=$ 0.000 memperhatikan bahwa nilai signifikan $P<a=0.05$. maka dapat disimpulkan bahwa ada hubungan antara pengetahuan dengan pemanfaatan posyandu lansia $\mathrm{Di}$ Desa Sikoran Kecamatan DAnau Paris Kabupaten Aceh Singkil.

Sebagian besar lansia yang tidak aktif ke posyandu mempunyai tingkat pengetahuan kurang. Lansia umumnya mempunyai kemampuan daya ingat yang menurun, sehingga mudah melupakan apa yang baru disampaikan dan ini berdampak pada tingkat pengetahuan para lansia yang masih kurang terutama
Setelah dilakukan uji statistik (uji Chi-Square), diperoleh nilai $P=$ 0.085 memperhatikan bahwa nilai signifikan $P>a=0,05$. maka dapat disimpulkan bahwa tidak ada hubungan antara dukungan keluarga dengan pemanfaatan posyandu lansia Di Desa Sikoran Kecamatan Danau Paris Kabupaten Aceh Singkil.

mengenai manfaat dan tujuan dari adanya posyandu lansia. Dengan pengalaman ini, pengetahuan lansia menjadi meningkat, yang menjadi dasar pembentukan sikap dan dapat mendorong minat atau motivasi mereka untuk selalu mengikuti kegiatan posyandu lansia (Saryati, 2018).

Pengetahuan lansia akan manfaat posyandu ini dapat diperoleh dari pengalaman pribadi dalam kehidupan sehari-harinya. Dengan menghadiri kegiatan posyandu, lansia akan mendapatkan penyuluhan tentang bagaimana cara hidup sehat dengan segala keterbatasan atau masalah kesehatan yang melekat pada mereka (Suseno, 2012).

Penelitian sebelumnya yang juga memperoleh hasil serupa adalah penelitian Siti Hajar dalam Kemalahayti, yang melaporkan bahwa hambatan mengikuti kegiatan 
posyandu lansia yaitu pendidikan usia lanjut yang rendah, pengetahuan usia lanjut yang kurang tentang manfaat posyandu, sikap usia lanjut yang negatif tentang posyandu usia lanjut dan kurangnya dukungan keluarga usia lanjut (Keumalahayati \& Alamsyah, 2018).

Hasil penelitian menunjukkan bahwasebanyak $57,9 \%$ lansia memiliki pengetahuan baik tentang pemanfaatan posyandu lansia. Hal ini mungkin disebabkan karena pengalaman yang pernah mereka dapat saat berkunjung ke posyandu lansia, dan informasi yang mereka dapat dari kader posyandu lansia.

Pengetahuan lansia akan manfaat posyandu ini dapat diperoleh dari pengalaman pribadi dalam kehidupan sehari-harinya. Dengan menghadiri kegiatan posyandu, lansia akan mendapatkan penyuluhan tentang bagaimana cara hidup sehat dengan segala keterbatasan atau masalah kesehatan yang melekat pada mereka. Dengan pengalaman ini, pengetahuan lansia menjadi meningkat, yang menjadi dasar pembentukan sikap dan dapat mendorong minat atau motivasi mereka untuk selalu mengikuti kegiatan posyandu lansia (Wahono, 2010).

Budi menyatakan bahwa pengetahuan adalah salah satu faktor penentu terbentuknya presepsi selain kebutuhan, pengalaman, suasana hati, ingatan, motivasi, serta perhatian sehingga bila pengetahuan sebagai salah satu faktor penentu terbentuknya presepsi baik maka dapat mengakibatkan terbentuknya presepsi yang baik pula.Pengetahuan pada hakekatnya merupakan segenap apa yang kita ketahui tentang suatu objek tertentu dan setiap jenis pengetahuan mempunyai ciri-ciri spesifik mengenai apa (ontology), bagaimana (epistemology), dan untuk apa (aksiology) pengetahuan tersebut (Yuniati \& Dewi, 2014)

Peneliti berasumsi bahwa sebagian besar responden masih memiliki pengetahuan kurang tentang pemanfaatan posyandu usia lanjut, hal ini diakibatkan oleh faktor pendidikan masyarakat yang rendah, dan tidak pernah mendapatkan informasi, yang akan berdampak terhadap rendahnya tingkat pengetahuan seseorang terhadap prilaku dan upaya kesehatan sehingga semakin rendah pula pemahamannya tentang posyandu usila dan semakin kurang juga keinginan untuk berkunjung ke posyandu usia lanjut.

Oleh karena itu, untuk meningkatkan pengetahuan lansia salah satunya dengan cara melakukan penyuluhan melalui kader-kader posyandu setempat, dengan sebelumnya para kader terlebih dahulu diberi pelatihan khusus tentang manfaat posyandu dan pentingnya keberadaan posyandu bagi lansia sehingga dengan adanya peningkatan pengetahuan oleh lansia diharapkan pemanfaatan posyandu akan berjalan dengan baik serta perlunya pemberian jadwal kegiatan secara terperinci setiap bulannya agar lansia dapat aktif mengikuti kegiatan sebagaimana yang telah tercantum pada jadwal kegiatan.

\section{Dukungan Keluarga Terhadap Pemanfaatan Posyandu Lansia di Desa Sikoran Kecamatan Danau Paris Kabupaten Aceh Singkil Tahun 2019.}

\footnotetext{
Yusraa ${ }^{1}$

${ }^{1}$ Dosen STIKes Putra Abadi Langkat Stabat

Email: yusraa925@gmail.com
} 
Setelah dilakukan uji statistik (uji Chi-Square), diperoleh nilai $P=$ 0.085 memperhatikan bahwa nilai signifikan $P>a=0,05$. maka dapat disimpulkan bahwa tidak ada hubungan antara dukungan keluarga dengan pemanfaatan posyandu lansia Di Desa Sikoran Kecamatan Danau Paris Kabupaten Aceh Singkil.

Hasil penelitian ini tidak sejalan dengan penelitian Purnawati yang menyatakan bahwa terdapat hubungan yang sangat signifikan antara dukungan keluarga dengan keaktifan lansia dalam mengikuti kegiatan Posyandu lansia (Purnawati \& Irdawati, 2014).

Dukungan Keluarga dapat
menjadi factor yang dapat berpengaruh dalam menentukan keyakinan dan nilai kesehatan individu serta menentukan program pengobatan yang akan mereka terima. Keluarga juga memberi dukungan dan membuat keputusan mengenai perawatan anggota keluarga yang sakit (Suseno, 2012).

Keluarga merupakan peranan penting dalam pembentukan nilainilai sosial membangunkan kesejahteraan, pengasuhan baru mengenai insitutisi keluarga. Peran keluarga disini adalah membantu lansia memecahkan masalah yang dihadapinya. Keluarga harus dapat meluangkan waktu untuk berbagi cerita, mendengarkan, memperhatikan, memberikan masukan atau solusi jika lansia sedang menghadapi masalah. Dukungan keluarga mampu meningkatkan semangat lansia menghadapi masa tuanya dengan baik dan dapat pula membentuk konsep diri yang baik (Idayani, Abi Muhlisin, Kep, \& Tomy, 2012).

Pada semua mementingkan keindividuan (individualistic) budaya masyarakat, tanggungjawab penjagaan, serta terlalu memberi penekanan kepada perawatan dan pengasuhan anak dibebankan ekonomi (economistic).Dalam konteks ini, kepada institusi keluarga (Hikmawati, 2014).

Hasil penelitian Zulkarnain dalam Anggraini juga menunjukkan bahwa faktor yang tidak berhubungan secara bermakna dengan tingkat kunjungan lansia ke posyandu adalah dukungan keluarga ( $p=0,944)$ (Anggraeni, n.d.).

Dukungan keluarga dapat mendorong para lansia untuk melaksanakan kegiatan posyandu lansia dengan baik. Peran keluarga adalah sebagai motivator atau memberikan masukan atau penyuluhan kesehatan beberapa informasi tentang kesehatan yang bermanfaat bagi kesehatan para lansia yang membantu lansia untuk meningkatkan kesehatan lansia (Fadhilah, 2012).

Dapat dilihat bahwa sebanyak $78,9 \%$ responden kurang dukungan keluarga sehingga banyak yang kurang memanfaatkan Posyandu Lansia. Oleh karena itu, Semakin baik dukungan keluarga yakni dukungan informasional, penilaian, instrumental dan emosional keluarga seseorang terhadap pemanfaatan Posyandu Lansia maka semakin baik juga pemanfaatan Posyandu Lansia.

Hal ini didukung oleh konsep teori Figley yang dikutip dari Marlina dalam Lumongga yaitu ikatan keluarga yang kuat sangat membantu anggota keluarga yang mengalami masalah. Dukungan semacam ini memungkinkan seseorang memperoleh kerekatan (kedekatan) emosional sehingga menimbulkan rasa aman bagi yang menerima. Orang yang menerima dukungan yang semacam ini merasa tenteram, aman, dan damai yang 
ditunjukkan dengan sikap tenang dan bahagia. Sumber dukungan paling sering dan umum diperoleh dari pasangan hidup, anggota keluarga, teman dekat dan sanak saudara (Lumongga \& Tukiman, 2013).

Keluarga merupakan support sys-temutama bagi lansia dalam memper-tahankan kesehatannya. Peranan keluarga dalam perawatan lansia antara lain menja-ga atau merawat lansia, mempertahankan 199dan meningkatkan status mental, mengan-tisipasi perubahan social ekonomi serta memberikan motivasi dan memfasilitasi kebutuhanspiritual bagi lansia (Maryam, 2008)

Keluarga mempunyai peran penting dalam pembinaan lanjutusia, baik di rumah maupun dalam kegiatan posyandu lanjut usia. Dukungan keluarga juga sangat berperan dalam mendorong minat dan kesedi-aan lansia untuk mengikuti kegiatan Po-syandu Lansia.Keluarga bisa menjadi moti-vator kuat bagi lansia apabila selalu me-nyediakan diri untuk mendampingi atau mengantar lansia ke posyandu, meng-ingatkan lansia jika lupa jadwal posyandu dan berusaha membantu mengatasi segala permasalahan bersama (Wahono, 2010)

Asumsi peneliti Dukungan keluarga memiliki peran penting terhadap lansia dalam pemanfaatan posyandu oleh lansia Dengan tidak adanya dukungan dari keluarga maka

\section{KESIMPULAN}

Berdasarkan hasil dan pembahasan Penelitian yang berjudul Pengaruh Pengetahuan Dan Dukungan Keluarga Terhadap Pemanfaatan Posyandu Usia Lanjut Di Desa Sikoran Kecamatan Danau Paris Kabupaten Aceh Singkil Tahun paralansia tidak mau datang ke posyandu apalagi bagi lansia yang tidak mapu lagi berjalan sendiriuntuk datang ke posyandu. Upaya yang dilakukan untuk mengantisipasi permasalahan iniadalah dengan memberikan arahan dan pemahaman kepada anggota keluarga betapapentingnya lansia datang ke Posyandu untuk memantau status kesehatanlansia setiapbulannya. Sehingga dapat mendeteksi secara dini gangguan kesehatan dan dapatmeningkatkan derajat kesehatan, dan usia harapan hidup lansia teersebut.

Kurangnya dukungan ini terjadi karena anak menganggap bahwa kegiatan posyandu kurangbermanfaat. Anak responden berpendapat bahwa lebih baik orang tua jika melakukan pemeriksaan kesehatan datang ke rumah sakit atau dokter. Selain itu anak pada umumnya mempunyai kesibukan tersendiri. Adanya kesibukan pada anggota keluarga akan mempengaruhi dalam bentuk dukungan sosial. ntuk meningkatkan dukungan keluarga dalam perilaku kunjun-gan lansia diposyandu sebaiknya para kader posyandu lansia dapat lebih aktif melakukan kunjungan rumah untuk memberikan informasi sosialisasi kegiatan po-syandu usila bukan hanya pada lansia, tetapi pada anggota keluarga lainnya

2015 dapat disimpulkan bahwa :Ada pengaruh yang bermakna dan signifikan antara pengetahuan terhadap pemanfaatan posyandu lanjut usia di Desa Sikoran Kecamatan Danau Paris Kabupaten Aceh Singkil Tahun 2019. Dengan
Yusraa $^{1}$

${ }^{1}$ Dosen STIKes Putra Abadi Langkat Stabat

Email: yusraa925@gmail.com 
nilai $P=0.000<P=0.05$. Tidak ada pengaruh dukungan keluarga Terhadap Pemanfaatan Posyandu Lanjut Usia Di Desa Sikoran Kecamatan Danau Paris Kabupaten Aceh Singkil Tahun 2019. Setelah dilakukan uji statistik (uji ChiSquare), Dengan nilai $P=0.085>$ $P=0.05$.

\section{SARAN}

Adapun saran yang dapat penulis sampaikan dari hasil penelitian ini adalah :

1. Bagi Puskesmas

Kepada pimpinan agar lebih meningkatkan manajemen Puskesmas khususnya pengawasan terhadap tenaga

\section{DAFTAR PUSTAKA}

Anggraeni, D. (n.d.). Hubungan Kebutuhan (Need) Lansia Dengan Pemanfaatan Posyandu Lansia Di Wilayah Kerja Puskesmas Sukorambi Kabupaten Jember.

Fadhilah, N. (2012). Faktor-Faktor Yang Berhubungan Dengan Pemanfaatan Posyandu Lansia Di Desa Blitarejo Kecamatan Gadingrejo Kabupaten Pringsewu Tahun 2012. Jurnal Ilmiah Kesehatan, 1(2).

Hikmawati, N. N. L. (2014). Hubungan Dukungan Keluarga Dan Peran Kader Dengan Keaktifan Lanjut Usia Dalam Mengikuti Kegiatan Di Posyandu Desa Pucangan Kartasura. Universitas Muhammadiyah Surakarta.

Idayani, T., Abi Muhlisin, S. K. M., Kep, M., \& Tomy, A. P. (2012). Hubungan Antara Pengetahuan Dan Sikap Lansia Dengan

Yusraa $^{1}$

${ }^{1}$ Dosen STIKes Putra Abadi Langkat Stabat

Email: yusraa925@gmail.com
Kesehatan dan dukungan dari kader posyandu lanjut usia agar dapat meningkatkan derajat kesehatan pada lanjut usia.

2. Bagi peneliti

Sebagai tambahan wawasan dan ilmu pengetahuan tentang pengetahuan dan dukungan keluarga terhadap pemanfaatan posyandu khususnya pada lanjut usia.

3. Bagi institusi pendidikan

Dapat menambah informasi bagi institusi pendidikan yang membaca tentang pengetahuan dan dukungan keluarga terhadap pemanfaatan posyandu lanjut usia.

Keaktifan Lansia Terhadap Pemanfaatan Posyandu Lansia Di Desa Windan Makamhaji Kartasura. Univesitas Muhammadiyah Surakarta.

Keumalahayati, K., \& Alamsyah, T. (2018). Hubungan Pengetahuan dan Dukungan Keluarga terhadap Kegiatan Posyandu Lansia. JKEP, 3(1), 1-14.

Kurniawati, E., \& Hasanah, S. (2019). FAKTOR-FAKTOR YANG BERHUBUNGAN DENGAN PEMANFAATAN POSYANDU LANSIA DI WILAYAH PUSKESMAS KUTA ALAM KOTA BANDA ACEH. JOURNAL OF HEALTHCARE TECHNOLOGY AND MEDICINE, 5(2), 262-269.

Latifah, D., Abi Muhlisin, H. M., SKM, M., \& Ambarwati, S. P. (2013). Perbedaan Kualitas Hidup Lansia Yang Aktif Mengikuti Posyandu Lansia Dengan Yang Tidak Aktif 
Mengikuti Posyandu Lansia Di Desa Sirnoboyo Kecamatan Pacitan. Universitas Muhammadiyah Surakarta.

Lumongga, N., \& Tukiman, T. (2013). Hubungan Perilaku Lansia dan Dukungan Keluarga terhadap Pemanfaatan Posyandu Lansia di Wilayah Kerja Puskesmas Darussalam Tahun 2012. Kebijakan, Promosi Kesehatan Dan Biostatistika, 1(2), 14382.

Maryam, S. (2008). Menengenal usia lanjut dan perawatannya. Penerbit Salemba.

Mengko, V. V. (2015). Pemanfaatan Posyandu Lansia di Wilayah Kerja Puskesmas Teling Atas Kota Manado. JIKMU, 5(5).

Nasution, Z. (2013). Pengaruh Pengetahuan, Sikap, Dukungan Keluarga dan Kader terhadap Pemanfaatan Posyandu Lanjut Usia di Wilayah Kerja Puskesmas Bandar Dolok Kecamatan Pagar Merbau Kabupaten Deli Serdang.

Novita, Y., Keswara, U. R., Wahyudi, W. T., \& Zainaro, M. R. (2014). Hubungan Dukungan Keluarga Dengan Kecemasan Pada Lansia Di Desa Bandar Jaya Wilayah Kerja Puskesmas Bandar Jaya Lampung Tengah. Holistik Jurnal Kesehatan, 8(2).

Purnawati, N., \& Irdawati, S. K. (2014). Faktor-Faktor Yang Mempengaruhi Kunjungan Lansia Dalam Kegiatan Posyandu Di Desa Plumbon Kec. Mojolaban Sukoharjoul.
Universitas Muhammadiyah Surakarta.

Saryati, D. (2018). Faktor-Faktor Yang Berhubungan Dengan Pemanfaatan Posyandu Lansia Di Puskesmas 7 Ulu Palembang Tahun 2017. Jurnal'Aisyiyah Medika, 1(2).

Suseno, D. M. (2012). Faktor-Faktor Yang Mempengaruhi Keaktifan Lansia Dalam Mengikuti Kegiatan Posyandu Lansia Di Desa Kauman Kecamatan Polanharjo Kabupaten Klaten. Universitas Muhammadiyah Surakrta.

Wahono, H. (2010). Analisis FaktorFaktor yang Mempengaruhi Pemanfaatan Posyandu Lansia Di Gantungan Makamhaji. Universitas Muhammadiyah Surakarta.

Yuniati, F., \& Dewi, Y. (2014). Pemanfaatan Posyandu Lanjut Usia. JPP (Jurnal Kesehatan Poltekkes Palembang), 2(14).

Zakir, M. (2017). Faktor-Faktor yang Berhubungan dengan Pemanfaatan Posyandu Lansia Kencana. Jurnal Ilmiah Keperawatan Sai Betik, 10(1), 64-69.

\footnotetext{
Yusraa ${ }^{1}$

${ }^{1}$ Dosen STIKes Putra Abadi Langkat Stabat

Email: yusraa925@gmail.com
} 